\title{
CHANGING TRENDS IN BACTERIAL SPECTRUM OF NEONATAL SEPSIS AT A TERTIARY CARE TEACHING HOSPITAL - 2011 TO 2015
}

\author{
Priyanka Sheshnath Prasad1', Gita Nataraj², Ruchi Nimish Nanavati³, Preeti Rajeev Mehta4
}

${ }^{1}$ Associate Professor, Department of Microbiology, Seth GS Medical College and KEM Hospital, Parel, Mumbai.

2 Professor, Department of Microbiology, Seth GS Medical College and KEM Hospital, Parel, Mumbai.

3 Professor and HOD, Department of Neonatology, Seth GS Medical College and HEM Hospital, Parel, Mumbai.

${ }^{4}$ Professor and HOD, Department of Microbiology, Seth GS Medical College and KEM Hospital, Parel, Mumbai.

\begin{abstract}
BACKGROUND

The organisms causing neonatal sepsis and their antimicrobial susceptibility patterns are highly diverse and vary geographically, temporally and locally attributed to changing pattern of antimicrobial use. Therefore, a continuous surveillance of sepsis is of utmost importance to ensure early diagnosis and appropriate therapy. This requires an understanding of changing trends in prevalent organisms and their antimicrobial susceptibility pattern. The aim of the present study was to determine the bacteriological p rofile and antimicrobial susceptibility pattern of organisms causing neonatal sepsis over a period of five years.
\end{abstract}

\section{METHODS}

This was a retrospective, hospital based single centre study. Microbiological data recorded from January 2011 to December 2015 was analysed. Blood cultures of all neonates with clinically suspected neonatal sepsis were included. Repeat isolation of the same species from the same neonate was excluded from analysis. Repeat blood cultures were advised when Coagulase-negative staphylococci (CoNS) were isolated.

\section{RESULTS}

Of a total of 10399 neonates included in the study, culture positivity was $12.1 \%$ over five years (Range $-10.4 \%$ to $15.7 \%$ ). CoNS remained the most commonly isolated organism over the five-year study period (36.2\%) with a high level of methicillin resistance. Enterobacteriaceae demonstrated high levels of resistance to all antibiotics tested. A similar rising trend in resistance for the years 2011 and 2014 was observed for non-fermenting Gram negative bacilli. A fall in percentage resistance to all antibiotics tested was observed in year 2015.

\section{CONCLUSIONS}

In spite of judicious antimicrobial use, a rising trend in antimicrobial resistance is observed. Improving infection control measures would perhaps help in controlling the spread of these resistant organisms.

\section{KEYWORDS}

Neonatal Sepsis, Drug Resistance, Antibiotic Policy, Infection Control.

HOW TO CITE THIS ARTICLE: Prasad PS, Nataraj G, Nanavati RN et al. Changing trends in bacterial spectrum of neonatal sepsis at a tertiary care teaching hospital - 2011 to 2015. J. Evolution Med. Dent. Sci. 2016;5(65):4628-4633, DOI: 10.14260/jemds/2016/1055

\section{INTRODUCTION}

Neonatal sepsis is a severe systemic syndrome in newborn infants characterised by signs of infection and accompanied by bacteraemia. It remains an important cause of morbidity and mortality in full term and low birth weight infants, despite advances in healthcare.(1) The incidence of neonatal sepsis varies with the geographical area, the socio-economic conditions and the customs followed in the perinatal period.(1) It has been seen that one in five neonates suffers from septicaemia in developing countries, which is responsible for $30-50 \%$ of total neonatal deaths annually. $(2,3)$ Diagnosis based on clinical presentation alone is difficult due to non-specific presenting signs and symptoms.(4) The organisms causing neonatal sepsis and their antimicrobial susceptibility patterns are highly diverse and vary geographically, temporally and

Financial or Other, Competing Interest: None.

Submission 05-07-2016, Peer Review 30-07-2016,

Acceptance 04-08-2016, Published 12-08-2016.

Corresponding Author:

Dr. Priyanka Sheshnath Prasad,

$7^{\text {th }}$ Floor, New Building,

Seth GS Medical College and KEM Hospital,

Parel, Mumbai-12.

E-mail: priyanka1975@gmail.com

DOI: $10.14260 /$ jemds/2016/1055 locally attributed to changing pattern of antimicrobial use. $(4,5)$ The spectrum of bacteria causing neonatal sepsis in the developing world is biased towards gram negative organisms as compared to the developed world where most of the cases involve group B streptococcus, E. coli and Listeria monocytogenes. $(6,7,8,9)$ Klebsiella pneumoniae, Staphylococcus aureus and E. coli are the most common organisms causing neonatal sepsis both in-hospital and in-community settings in India followed by Acinetobacter species and Pseudomonas species. $(2,5,10)$ The infants who survive the episode of neonatal sepsis are vulnerable to short- and long-term neurodevelopmental morbidity. Thus, a continuous surveillance of sepsis is of utmost importance to ensure early diagnosis and appropriate therapy.(3,7) This requires an understanding of changing trends in prevalent organisms and their antimicrobial susceptibility pattern.

This study was conducted in King Edward Memorial hospital, a 2250 bedded tertiary care multi-speciality teaching hospital in the city of Mumbai, which caters to a population predominantly from Mumbai and other parts of Maharashtra. The NICU has 42 beds with approximately 1800-2000 admissions per year. Admitted neonates are either those delivered in the hospital itself or those that were delivered 
outside and have been admitted for intensive care. The observation of a higher proportion of susceptible isolates and a higher isolation of Klebsiella pneumoniae and Acinetobacter species in 2015 compared to the previous year prompted the present study with an aim to determine the bacteriological profile and antimicrobial susceptibility pattern of organisms causing neonatal sepsis over a period of five years from January 2011 to December 2015 and to observe any trends in frequency distribution of different aerobic bacterial species and the proportion of resistant isolates.

\section{MATERIAL AND METHODS}

This was a retrospective, hospital based single centre study. Microbiological data recorded from January 2011 to December 2015 were analysed. The requisition form captures data pertaining to patient demographics, clinical diagnosis, antibiotic use if any and nature of test requisitioned. Blood cultures of all neonates with clinically suspected neonatal sepsis were included. As a policy, blood cultures are collected prior to initiating antibiotic therapy and incubated aerobically. Repeat isolation of the same species from the same neonate was excluded from analysis. Repeat blood cultures were advised when CoNS were isolated. For the purpose of the study, diphtheroids, Micrococcus spp., Bacillus species and viridans group streptococci were considered contaminants.(11) The blood specimens were processed for isolation of aerobic bacteria as per standard protocol using trypticase soy broth and subcultured on days two, four and six onto 5\% sheep blood agar and MacConkey's agar and incubated aerobically at $37^{\circ} \mathrm{C}$. Any clinically significant isolate obtained was identified by standard phenotypic methods upto species level.(12) Antimicrobial susceptibility testing was performed and interpreted as per CLSI standards updated from time to time either by Kirby-Bauer disk diffusion method if recommended for all the years or MIC where required (colistin and vancomycin) by using E test strips (Ezy MICTM strips, HiMedia Laboratories Pvt. Ltd). Clinical significance of the isolate was ascertained after discussion with neonatologist. A positive blood culture in the presence of clinical signs and symptoms of infection was defined as sepsis.

\section{Ethics}

Institutional Ethics Committee permission was taken before commencing the study (IEC (II)/OUT/141/16).

\section{Statistical Analysis}

For the purpose of the present study, post-hoc, the analysis has been broken up into two sets: 2011-2014 (which saw an increasing resistance trend) and 2014-2015 (which saw a decreasing resistance trend). Data was analysed using SPSS software for windows. Different data sets (trends in culture positivity rate, frequency distribution of different species, antimicrobial susceptibility rates of each species) were compared using Fisher's exact test. $\mathrm{P} \leq 0.05$ was considered significant.

\section{RESULTS}

A total of 10399 neonates were included in the study. Culture positive sepsis was $12.1 \%$ over five years (Range $-9.2 \%$ to $15.7 \%$ ) (Table 1). Monobacterial infection was seen in 1228 blood cultures, whereas more than one organism (two organisms) was seen in 15 blood cultures giving 1258 isolates. An overall contamination rate of $0.53 \%$ was observed.

Bacterial spectrum of neonatal sepsis is depicted in Table 1. Coagulase negative staphylococci remained the most commonly isolated organism over the five-year study period (36.2\%) with a high level of methicillin resistance (307/455, $67.5 \%$ ). Most common species amongst CoNS was $S$. epidermidis (58.02\%) (Table 2). All methicillin resistant strains were susceptible to vancomycin with MIC range of $0.032-0.25 \mu \mathrm{g} / \mathrm{mL}$ for MRSA and $0.125-1.0 \mu \mathrm{g} / \mathrm{mL}$ for MRCoNS.

Enterobacteriaceae demonstrated high levels of resistance to all antibiotics tested (Table 3). Higher rate of resistance was observed for meropenem as compared to imipenem. For the period 2011-2014, the increasing trend in resistance was observed for all antibiotics tested except gentamicin, ciprofloxacin and ceftriaxone and was found to be statistically significant (Table 4). A fall in percentage resistance to all antibiotics tested was observed in year 2015 as compared to 2014 except for ceftriaxone and ceftazidime (Table 3). This reduction was found to be statistically significant (Table 4).

Susceptibility to colistin for Acinetobacter spp. was $88.9 \%$. MIC for susceptible strains ranged between $0.25-1.0 \mu \mathrm{g} / \mathrm{mL}$. A rising trend in resistance for the years 2011 and 2014 was observed for non-fermenting Gram negative bacilli (Table 5). Levofloxacin demonstrated lower resistance compared to other antibiotics. Imipenem resistance was higher as compared to meropenem. For most antibiotics, resistance decreased in 2015 compared to the previous years. The statistical significance of this difference is given in Table 4 .

\begin{tabular}{|c|c|c|c|c|c|c|}
\hline & 2011 & 2012 & 2013 & 2014 & 2015 & Overall \\
\hline Number of blood cultures screened & 2193 & 1963 & 2366 & 2025 & 1853 & 10399 \\
\hline$\%$ culture positive & $10.4 \%$ & $15.7 \%$ & $13.7 \%$ & $9.2 \%$ & $11.4 \%$ & $12.1 \%$ \\
\hline Total isolates & 228 & 308 & 325 & 186 & 211 & 1258 \\
\hline \multirow{2}{*}{$\begin{array}{l}\text { Non-fermenting Gram negative bacilli } \\
\text { - } \quad \text { Acinetobacter species } \\
\text { - } \quad \text { P. aeruginosa } \\
\text { - } \quad \text { Other NF-GNB }\end{array}$} & $52(22.4 \%)$ & $76(24 \%)$ & $101(30.1 \%)$ & $53(28.2 \%)$ & $4522.3 \%)$ & $327(25.4 \%)$ \\
\hline & $\begin{array}{c}25(11 \%) \\
16(7 \%) \\
11(4.8 \%)\end{array}$ & $\begin{array}{c}56(18.2 \%) \\
12(3.9 \%) \\
8(2.6 \%)\end{array}$ & $\begin{array}{c}37(11.4 \%) \\
8(2.5 \%) \\
54(16.6 \%)\end{array}$ & $\begin{array}{c}22(11.8 \%) \\
8(4.3 \%) \\
20(10.8 \%)\end{array}$ & $\begin{array}{c}44(20.9 \%) \\
2(1 \%) \\
2(0.9 \%)\end{array}$ & $\begin{array}{c}186(14.8 \%) \\
46(3.7 \%) \\
95(7.6 \%)\end{array}$ \\
\hline \multirow{4}{*}{$\begin{array}{l}\text { Enterobacteriaceae } \\
\text { - } \quad \text { E. coli } \\
\text { - } \quad \text { K. pneumonia } \\
\text { - } \quad \text { Other Enterobacteriaceae }\end{array}$} & $34(14.9 \%)$ & $\begin{array}{c}60 \\
(18.9 \%)\end{array}$ & $83(24.8 \%)$ & $49(26 \%)$ & $\begin{array}{c}46 \\
(21.8 \%)\end{array}$ & $\begin{array}{c}272 \\
(21.6 \%)\end{array}$ \\
\hline & $3(1.3 \%)$ & $13(4.1 \%)$ & $16(4.9 \%)$ & $5(2.7 \%)$ & $6(2.8 \%)$ & $38(2.9 \%)$ \\
\hline & $20(8.6 \%)$ & $25(7.9 \%)$ & $45(13.1 \%)$ & $37(9.7 \%)$ & $32(15.2 \%)$ & $159(10.9 \%)$ \\
\hline & $11(4.8 \%)$ & $22(7.1 \%)$ & $22(6.8 \%)$ & $7(3.8 \%)$ & $8(3.8 \%)$ & $70(5.6 \%)$ \\
\hline
\end{tabular}




\begin{tabular}{|c|c|c|c|c|c|c|}
\hline S. aureus (MS)* & $9(4 \%)$ & $6(2 \%)$ & $7(2.2 \%)$ & $16(8.6 \%)$ & $8(3.8 \%)$ & $46(4.1 \%)$ \\
\hline MRSA $\dagger$ & $3(1.3 \%)$ & $9(2.9 \%)$ & $5(1.5 \%)$ & $3(1.6 \%)$ & $2(0.9 \%)$ & $22(1.6 \%)$ \\
\hline CoNS $\neq(M S)^{*}$ & $47(20.6 \%)$ & $43(14 \%)$ & $9(2.8 \%)$ & $5(2.7 \%)$ & $44(20.9 \%)$ & $148(12.2 \%)$ \\
\hline MRCoNS § & $57(25 \%)$ & $90(29.2 \%)$ & $78(24 \%)$ & $43(23.12 \%)$ & $39(18.5 \%)$ & $307(24 \%)$ \\
\hline Enterococcus species & $11(4.8 \%)$ & $20(6.5 \%)$ & $29(8.9 \%)$ & $6(3.2 \%)$ & $4(1.9 \%)$ & $70(5.6 \%)$ \\
\hline Candida species & $10(4.3 \%)$ & $4(1.3 \%)$ & $10(3 \%)$ & $7(3 \%)$ & $16(7.6 \%)$ & $47(3.7 \%)$ \\
\hline Others & $5(2.2 \%)$ & 0 & $3(0.9 \%)$ & $4(2.2 \%)$ & $7(3.3 \%)$ & $19(1.5 \%)$ \\
\hline
\end{tabular}

*MS=Methicillin susceptible †MRSA=Methicillin resistant Staphylococcus aureus

$\ddagger$ CoNS = Coagulase negative Staphylococci §MRCoNS= Methicillin resistant Coagulase negative Staphylococci

\begin{tabular}{|c|c|c|c|c|c|c|}
\hline & $\mathbf{2 0 1 1}$ & $\mathbf{2 0 1 2}$ & $\mathbf{2 0 1 3}$ & $\mathbf{2 0 1 4}$ & $\mathbf{2 0 1 5}$ & Total \\
\hline MS-CoNS & $47(20.6 \%)$ & $43(14 \%)$ & $9(2.8 \%)$ & $5(2.7 \%)$ & $44(20.9 \%)$ & $148(12.2 \%)$ \\
\hline S. epidermidis & $24(51 \%)$ & $27(62.8 \%)$ & $5(55.6 \%)$ & $3(60 \%)$ & $26(59.1 \%)$ & $85(57.4 \%)$ \\
\hline S. haemolyticus & $19(40.4 \%)$ & $12(27.9 \%)$ & $3(33.3 \%)$ & $1(20 \%)$ & $11(25 \%)$ & $46(31.1 \%)$ \\
\hline S. warneri & $4(8.5 \%)$ & $3(7 \%)$ & 0 & $1(20 \%)$ & $5(11.1 \%)$ & $13(8.8 \%)$ \\
\hline S. lugdunensis & 0 & $1(2.3 \%)$ & $1(11.1 \%)$ & 0 & $2(4.5 \%)$ & $4(2.7 \%)$ \\
\hline MR-CoNS & $57(25 \%)$ & $90(29.2 \%)$ & $78(24 \%)$ & $43(23.12 \%)$ & $39(18.5 \%)$ & $307(24 \%)$ \\
\hline S. epidermidis & $32(56.1 \%)$ & $54(60 \%)$ & $49(62.8 \%)$ & $23(53.3 \%)$ & $21(53.8 \%)$ & $179(58.3 \%)$ \\
\hline S. haemolyticus & $17(29.8 \%)$ & $21(23.3 \%)$ & $22(28.2 \%)$ & $12(27.9 \%)$ & $11(28.2 \%)$ & $83(27 \%)$ \\
\hline S. warneri & $5(8.8 \%)$ & $9(10 \%)$ & $5(6.4 \%)$ & $4(9.3 \%)$ & $4(10.3 \%)$ & $27(8.8 \%)$ \\
\hline S. lugdunensis & $3(5.3 \%)$ & $6(6.7 \%)$ & $2(2.6 \%)$ & $4(9.3 \%)$ & $3(7.7 \%)$ & $18(5.9 \%)$ \\
\hline \multicolumn{7}{|l|}{ Table 2: Speciation of CoNS (Coagulase Negative Staphylococcus) Isolates } \\
\hline
\end{tabular}

\begin{tabular}{|c|c|c|c|c|c|c|}
\hline \multicolumn{7}{|c|}{$\mathrm{N}=272$} \\
\hline Antibiotic & 2011 & 2012 & 2013 & 2014 & 2015 & Overall \\
\hline Gentamicin & 50.0 & 50.9 & 57.3 & 60.5 & 13.6 & 46.46 \\
\hline Amikacin & 33.3 & 35.6 & 64.4 & 63.6 & 8 & 40.98 \\
\hline Ciprofloxacin & 56.3 & 51.8 & 44.4 & 65.2 & 20 & 47.54 \\
\hline $\begin{array}{l}\text { Piperacillin- } \\
\text { tazobactam }\end{array}$ & 34.4 & 64.9 & 79.7 & 77.8 & 42 & 59.76 \\
\hline Imipenem & 0.0 & 24.1 & 60.3 & 41 & 0 & 25.08 \\
\hline Meropenem & 4.2 & 40.3 & 66.3 & 52.5 & 47.8 & 25.08 \\
\hline Ceftriaxone & 60.9 & 81.8 & 72.4 & 65.9 & 72.4 & 42.22 \\
\hline Ceftazidime & 88.9 & 84.6 & 91.2 & 40 & 67.6 & 70.68 \\
\hline Cefepime & 46.4 & -- & 86.8 & 76.3 & 57.1 & 74.46 \\
\hline
\end{tabular}

\begin{tabular}{|c|c|c|c|c|c|}
\hline \multicolumn{3}{|c|}{ Enterobacteriaceae (p) } & \multicolumn{3}{c|}{ NF-GNB (p) } \\
\hline Antibiotic & $\mathbf{2 0 1 1 - 2 0 1 4}$ & $\mathbf{2 0 1 4 - 2 0 1 5}$ & Antibiotic & $\mathbf{2 0 1 1 - 2 0 1 4}$ & $\mathbf{2 0 1 4 - 2 0 1 5}$ \\
\hline Gentamicin & 0.3706 & $0.0001^{*}$ & Gentamicin & $0.0002^{*}$ & 0.309 \\
\hline Amikacin & $0.0075^{*}$ & $0.0001^{*}$ & Amikacin & $0.0059^{*}$ & $0.0273^{*}$ \\
\hline Ciprofloxacin & 0.4923 & $0.0001^{*}$ & Levofloxacin & 0.0926 & 0.8346 \\
\hline $\begin{array}{c}\text { Piperacillin- } \\
\text { tazobactam }\end{array}$ & $0.0002^{*}$ & $0.0004^{*}$ & $\begin{array}{c}\text { Piperacillin- } \\
\text { tazobactam }\end{array}$ & $0.0002^{*}$ & 0.1612 \\
\hline Imipenem & $0.0001^{*}$ & $0.0001^{*}$ & Imipenem & $0.0214^{*}$ & $0.0441^{*}$ \\
\hline Meropenem & $0.0001^{*}$ & 0.8383 & Meropenem & $0.0001^{*}$ & 0.539 \\
\hline Ceftriaxone & 0.8179 & 0.5174 & Ceftazidime & 0.3272 & 0.2208 \\
\hline Ceftazidime & $0.0001^{*}$ & $0.0134^{*}$ & Cefepime & 0.2267 & $0.0011^{*}$ \\
\hline Cefepime & $0.0108^{*}$ & 0.0552 & & & \\
\hline \multicolumn{7}{|c|}{ Table 4: Changing Trend in Antibiotic Resistance } \\
\end{tabular}




\begin{tabular}{|c|c|c|c|c|c|c|}
\hline \multicolumn{7}{|c|}{$\mathbf{N = 3 2 7}$} \\
\hline Antibiotic & $\mathbf{2 0 1 1}$ & $\mathbf{2 0 1 2}$ & $\mathbf{2 0 1 3}$ & $\mathbf{2 0 1 4}$ & $\mathbf{2 0 1 5}$ & 0verall \\
\hline Gentamicin & 25.0 & 34.9 & 31.4 & 61.9 & 50 & 40.64 \\
\hline Amikacin & 30.8 & 63.0 & 50.5 & 57.7 & 34.6 & 47.32 \\
\hline Levofloxacin & 22.7 & 25.4 & 21.1 & 40.5 & 35 & 28.94 \\
\hline $\begin{array}{c}\text { Piperacillin- } \\
\text { tazobactam }\end{array}$ & 45.7 & 53.5 & 58.0 & 54.2 & \multirow{2}{*}{40} & \multirow{2}{*}{50.28} \\
\hline Imipenem & 21.1 & 31.8 & 30.4 & 43.2 & 64.7 & 38.24 \\
\hline Meropenem & 10.3 & 39.2 & 37.7 & 46.0 & 37.5 & 34.14 \\
\hline Ceftazidime & 61.1 & 85.0 & 72.9 & 51.5 & 63.6 & 66.82 \\
\hline Cefepime & 57.9 & 0.0 & 69.6 & 36.4 & 32.78 \\
\hline
\end{tabular}

\section{DISCUSSION}

A decreasing resistance trend in 2015 as compared to the previous years prompted the present study to determine the changing trend if any in antimicrobial spectrum and susceptibility pattern over a five-year period. The gold standard for confirmation of sepsis is blood culture. The blood culture positivity rate in the present study was $12.1 \%$. This rate is lower than that reported in other studies. $(2,3,13)$ Low isolation rates have also been reported in other studies. $(14,15)$ Factors responsible for lower yield in blood culture in the presence of sepsis include inadequate volume of blood cultured, patients receiving antibiotics, inappropriate timing of culture, type of culture medium used, an inappropriate presumptive diagnosis and presence of other fastidious organisms or anaerobes. $(14,16,17)$ The volume of blood that can be collected in a neonate cannot be increased, as it is difficult and unsafe to collect more than $1 \mathrm{~mL}$ of blood.(8,17) As per the hospital protocol, blood is sent for culture before initiating antibiotics, but as this is a tertiary care centre, some extramural neonates may have received antibiotics elsewhere before presenting to this hospital. Appropriate timing for collection of blood for culture is not well defined in neonates.(17) Since antibiotics have to be started as soon as presumptive diagnosis is made, the timing of collection may not be appropriate. Since only aerobic cultures were done and fastidious organisms were not specifically looked for by using special media, these organisms could have been missed. $(4,14,15)$ Another limitation of this study was that conventional blood culture was performed as automation was not available.

The other finding of this study was that in a majority of patients, blood stream infections were mono-microbial. Studies have reported that $6 \%$ to $21 \%$ of all true bacteraemias are polymicrobial.(18)

In the present study, gram negative bacteria accounted for $46.9 \%$ of total isolates. Amongst Gram negative bacilli, Acinetobacter species (14.8\%) and Klebsiella pneumoniae $(10.9 \%)$ were the predominant pathogens. Other studies have also reported a higher preponderance of gram negative bacteria and similar individual pathogen preponderance. $(2,3,10,13,14,19,20,21)$

The aetiological agents for sepsis in developing countries generally tend to be gram negative bacteria. The reasons for this could be multi-factorial. At birth, neonates lack normal flora. During the peripartum period and subsequently the neonates are exposed to gram negative bacilli both in the mother's birth canal and in the immediate surrounding environment. This may lead to colonization with these organisms. Considering the lower levels of immunity in the neonates, especially the absence of $\operatorname{IgM}$ antibodies, the colonizers can become opportunistic pathogens. Also, the selective pressure due to antimicrobial use in this population can predispose to colonization and proliferation of these organisms in neonates. $(2,22)$

In the present study, high levels of resistance to the commonly prescribed antibiotics for Enterobacteriaceae was observed. The most effective antibiotics for Klebsiella in-vitro excluding polymyxin B and colistin (100\% sensitivity) was imipenem (92.8\%) followed by amikacin $(77.2 \%)$, piperacillin and cefotaxime (66.7\%). High levels of resistance of Klebsiella species to multiple antibiotics has also been reported in other studies. $(2,14,23)$

For Acinetobacter species except colistin (sensitivity $100 \%$ and $88.9 \%$ ), all other antibiotics had a very low sensitivity (ampicillin, piperacillin, imipenem and cefotaxime have sensitivity of $50 \%$ each giving very few treatment options). Kumar et al have demonstrated resistance of Acinetobacter species to all antibiotics including carbapenems in high numbers. In recent years, Acinetobacter species have emerged as major threats for infections in immunocompromised host population like neonates with resistance to most of the commonly used drugs. $(2,19)$

Amongst gram positive species, Staphylococci species were isolated in $41.9 \%$ cases, of which majority were Coagulase negative staphylococci $(36.2 \%)$. CoNS are the commonest cause of Late Onset Sepsis (LOS).(11) During the first week of life, neonates get rapidly colonized with environmental microorganisms. The use of central venous catheters, mechanically assisted ventilation, exposure to other invasive procedures, parenteral nutrition and low immunity in the infant greatly increases the risk of CoNS infection. Rarely, they may acquire the infection vertically. The isolation of CoNS in neonatal blood cultures poses a difficulty, since these organisms can occur as contaminants or pathogens in this population.(18) To overcome this diagnostic dilemma, Centres for Disease Control and Prevention (CDC, USA) has proposed it to be considered as a true pathogen.(24) In the present study, the second blood culture was not obtained in most of the neonates in whom CoNS was isolated. The clinical significance was established based on consultation with neonatologist. Almost all babies in the present study had a vascular line, which may have contributed to the higher rate of occurrence of CoNS. The rate of MRSA isolation in this study varied from 1-3\% over the 5year study period. Methicillin resistance in CoNS was higher (25\% in 2011, which came down to $18.5 \%$ in 2015).

As per the NICU antibiotic policy of this hospital, the first line therapy for neonatal sepsis comprises a combination of amoxicillin-clavulanic acid or ampicillin-sulbactam with amikacin. If this therapy fails, the second line includes cefuroxime or piperacillin-tazobactam with amikacin and only in the case of failure of treatment is the patient given 
carbapenem very judiciously. Vancomycin or linezolid is administered only in culture proven MRSA cases. (Guidelines for antimicrobial therapy and prophylaxis, 2014-15, Version 1.1, Brihanmumbai Municipal Corporation, Mumbai, Maharashtra, India).

In comparison to the trends seen till 2014, in 2015, there was a sudden unexplained drop in resistance to many of the routinely used antibiotics (Table 3 and 4). Considering that neonates with clinical suspicion of sepsis belong to high risk category (pre-term, low birth weight) with its associated morbidity and mortality, empiric antibiotic therapy was initiated. The antibiotic policy for the study period remained the same. The type of neonates admitted also did not change. The only change during this period was a civil renovation between April 2015 and November 2015, followed by strengthening of infection control measures.

During this period, the neonates were shifted to another ward in the hospital premises, which was previously occupied by non-infectious patients. It is possible that this could have resulted in source (environmental) reduction. There was a complete civil remodelling of NICU based on level of treatment provision and keeping infection control practices in mind. The air handling unit was changed with twelve air changes per hour. Once the NICU was re-commissioned, the infection control practices were strengthened. Hand hygiene was given a major thrust. All staff had to complete the training on infection control. Environmental hygiene was supervised. It is assumed that all these measures may have contributed to the decrease in resistance rates between 2014 and 2015. Various studies have effectively demonstrated that improvement of infection control procedures such as diligent hand hygiene, proper cleaning and disinfection methods and aseptic practices are linked to lower health care associated infection rates as well as reduction in multidrug-resistant organism transmission and acquisition.(25,26) Since this was a retrospective study, analysis of sepsis as early or late onset was not undertaken since these data were not available.

\section{CONCLUSION}

In spite of judicious antimicrobial use, a rising trend in antimicrobial resistance is observed. In such situations, improving infection control measures would at least mitigate transmission of resistant organisms.

\section{REFERENCES}

1. Yilmaz NO, Agus N, Helvaci M, et al. Change in pathogens causing late-onset sepsis in neonatal intensive care unit in Izmir, Turkey. Iran J Pediatr 2010;20(4):451-8.

2. Muley VA, Ghadage DP, Bhore AV. Bacteriological profile of neonatal septicemia in a tertiary care hospital from Western India. Journal of Global Infectious Diseases 2015;7(2):75-7.

3. Sharma CM, Agrawal RP, Sharan H, et al. Neonatal sepsis: bacteria \& their susceptibility pattern towards antibiotics in neonatal intensive care unit. J Clin Diagn Res 2013;7(11):2511-3.

4. Shehab El-Din E, El-Sokkary M, Bassiouny MR, et al. Epidemiology of neonatal sepsis and implicated pathogens: a study from Egypt. Bio Med Research International 2015;2015:1-11.
5. Sivanandan S, Soraisham A, Swarnam K. Choice and duration of antimicrobial therapy for neonatal sepsis and meningitis. International Journal of Pediatrics 2011;2011:1-9.

6. Nikkhoo B, Lahurpur F, Delpisheh A, et al. Neonatal blood stream infections in tertiary referral hospitals in Kurdistan, Iran. Ital J Pediatr 2015;41(1):43.

7. Bhat RY, Lewis LES, KE V. Bacterial isolates of early-onset neonatal sepsis and their antibiotic susceptibility pattern between 1998 and 2004: an audit from a center in India. Italian Journal of Pediatrics 2011;37:32.

8. Kiwanuka J, Bazira J, Mwanga J, et al. The microbial spectrum of neonatal sepsis in Uganda: recovery of culturable bacteria in mother-infant pairs. PLoS ONE 2013;8(8):e72775.

9. Srivastava R, Agarwal J, Srivastava $S$, et al. Multidrug resistant gram-negative bacilli from neonatal septicaemia at a tertiary care centre in North India: a phenotypic and genotypic study. Indian Journal of Medical Microbiology 2014;32(1):97-98.

10. Marwah P, Chawla D, Chander J, et al. Bacteriological profile of neonatal sepsis in a tertiary care hospital of Northern India. Indian Pediatrics 2015;52:158-9.

11. Ballot D, Nana T, Sriruttan C, et al. Bacterial Bloodstream Infections in neonates in a developing country. ISRN Pediatrics 2012:1-6.

12. Winn W, Koneman E. Koneman's color atlas and textbook of diagnostic microbiology. Philadelphia: Lippincott Williams \& Wilkins 2006.

13. Tayade N, Rajyadhyaksha S. Neonatal sepsis: culture and sensitivity pattern at tertiary level neonatal intensive care unit. International Journal of Innovative Research and Review 2015;3(2):1-7.

14. Jyothi P, Basavaraj M, Basavaraj P. Bacteriological profile of neonatal septicemia and antibiotic susceptibility pattern of the isolates. Journal of Natural Science, Biology and Medicine 2013;4(2):306-9.

15. Shrestha P, Das BK, Bhatta $N$, et al. Clinical and bacteriological profiles of blood culture positive sepsis in newborns. Journal of Nepal Paediatric Society 2009;27(2).

16. Marchant EA, Boyce GK, Sadarangani M, et al. Neonatal sepsis due to coagulase-negative staphylococci. Clinical and Developmental Immunology 2013;2013:1-10.

17. Paolucci M, Landini MP, Sambri V. How can the microbiologist help in diagnosing neonatal sepsis? International Journal of Pediatrics 2012;2012:1-14.

18. Hall KK, Lyman JA. Updated review of blood culture contamination. Clinical Microbiology Reviews 2006;19(4):788-802.

19. Kumar A, Randhawa V, Nirupam N, et al. Risk factors for carbapenem-resistant Acinetobacter baumannii blood stream infections in a neonatal intensive care unit, Delhi, India. J Infect Dev Ctries 2014;8(8):1049-54.

20. Lamba M, Sharma R, Sharma D, et al. Bacteriological spectrum and antimicrobial susceptibility pattern of neonatal septicaemia in a tertiary care hospital of North India. The Journal of Maternal-Fetal \& Neonatal Medicine 2016:1-6. 
21. Viswanathan R, Singh A, Basu S, et al. Multi-drugresistant, non-fermenting, gram-negative bacilli in neonatal sepsis in Kolkata, India: a 4-year study. Paediatrics and International Child Health 2013;34(1):56-9.

22. Overall JC. Neonatal bacterial meningitis. The Journal of Pediatrics 1970;76(4):499-511.

23. Thakur S, Thakur K, Sood A, et al. Bacteriological profile and antibiotic sensitivity pattern of neonatal septicaemia in a rural tertiary care hospital in North India. Indian Journal of Medical Microbiology 2016;34(1):67-71.
24. Horan TC, Andrus M, Dudeck MA. CDC/NHSN surveillance definition of health care -associated infection and criteria for specific types of infections in the acute care setting. Am J Infect Control. 2008; 36:309-32.

25. Whitelaw A. Role of infection control in combating antibiotic resistance. S Afr Med J 2015;105(5):421.

26. Bizzarro M, Shabanova V, Baltimore R, et al. Neonatal sepsis 2004-2013: the rise and fall of coagulase-negative staphylococci. J Pediatric 2015;166(5):1193-9. 